\title{
CHANGES IN HUMAN MUSCLES AFTER PERMANENT TENOTOMY*
}

\author{
BY \\ S. SUNDERLAND and J. O. LAVARACK \\ From the Department of Anatomy and Histology, University of Melbourne, Australia
}

There is an extensive literature on the "disuse" atrophy of muscle produced by a variety of techniques, in a variety of experimental animals and with different muscles, but usually those of the calf, forming the subject of study. Accounts of this condition in human muscles, however, appear to be limited to passing references in the clinical literature to the wasting which follows the immobilization of limbs and to a brief note by Smith (1928) on the histological structure of a muscle attached solely to the shaft of the fibula. The great difficulty of obtaining suitable human material for weight loss and histological studies is obvious, though the possibilities of investigating disuse phenomena in the muscles after tenotomy of amputation stumps does not appear to have been appreciated. Admittedly the normal and affected limbs of deceased amputees are rarely available for unhurried dissection but when this does become possible the opportunity should be taken of adding to our data on atrophy after tenotomy in human muscles. Recently the authors had an opportunity of performing two such dissections and the observations made on this material form the subject matter of this paper.

\section{MATERIAL AND METHODS}

Subject 1.-The right hand of H.T., a male, aged 76, had been amputated through the radio-carpal joint 20 years before death. Movements at and above the elbow joint were not impaired. The body was embalmed within 24 hours of death and then stored in formalin. When dissected, the normal and affected arms were in an excellent state of preservation. Dissection revealed normal radio-ulnar joints though pronation and supination were limited in range. On the involved side the severed tendons had become adherent to the distal extremities of the radius and ulna. The arrangement of the forearm muscles permitted their subdivision into four groups.

Group 1.-Tenotomized muscles taking origin below the elbow joint of which the severed tendons were ad-

*This work was assisted by a grant from the National Health and Medical Research Council of Australia. herent to the stump; these were unable to shorten. This group was represented by the abductor pollicis longus, extensor pollicis brevis, extensor pollicis longus, flexor pollicis longus, flexor digitorum profundus, and extensor indicis proprius.

Group 2.-Tenotomized muscles arising from the lower end of the humerus of which the tendons originally passed to an attachment in the hand but were now adherent to the stump; normally this group contributes little to movements at the elbow joint. However, the disposition of the muscles with reference to this joint was such that, during life, they would have been affected by movements of the forearm and would also have been free to shorten. This group could be further subdivided into:

(a) Those muscles taking origin solely from the humerus (radial flexors and extensors of the wrist, palmaris longus, extensor digitorum communis); and (b) those muscles gaining an additional origin from one of the bones of the forearm (ulnar flexor and extensor of the wrist and flexor digitorum sublimis).

Group 3.-The supinator and pronators of which the attachments were undisturbed but specific functions were curtailed. This group could be further subdivided into the humeral heads of the pronator teres and supinator, which cross the elbow joint, and the deep heads of these muscles plus the pronator quadratus which join the radius and the ulna.

Group 4.-Muscles with attachments and functions which were not disturbed by the amputation, e.g., the brachioradialis.

Each muscle was carefully isolated and removed, tendons being divided at corresponding levels on the two sides. The muscles were immediately weighed and then transferred to $10 \%$ formalin. There are several sources of error in obtaining the weight of wet specimens and in employing, as was the method adopted in this study, the weight of the corresponding normal muscle as the pre-operative weight of the involved muscle for calculating the percentage atrophy. Those errors have been detailed by Langley $(1916,1917)$ and Langley and Hashimoto (1918). All the precautions outlined by them were observed in the present enquiry.

The muscles were submitted to a standard histological procedure. After fixation in formalin a block was taken at the mid-point of the belly of each muscle. After embedding the material in paraffin in the usual manner, transverse sections, $10 \mu$ in thickness, were prepared from 
the faces of the block. The remainder of the block was then sectioned longitudinally at $10 \mu$. The sections were stained with haematoxylin and eosin and Van Gieson.

Subject 2.-S.W., a male, aged 40 years, had a midthigh amputation on the right side 10 months before death. The dissection of this subject was performed in the necropsy room. The level of the amputation prevented a study of weight loss but provided material for the histological examination of tenotomized muscle. Blocks of tissue were removed from the affected and normal hamstring muscles. In this case, however, no muscles had been rendered completely functionless by the operation. The hamstrings, for example, continued to aid extension at the hip joint. The muscle tissue removed for histological study was prepared in the same way as that obtained from Subject 1.

\section{MACROSCOPIC FEATURES}

The tenotomized muscles (Groups 1 and 2) were distinctly paler than the normal muscles but despite this they retained their general form and a colour and texture which identified them as muscles. There was no suggestion of a yellowish or translucent appearance and no macroscopic evidence of any conversion into ill-defined fibrous tissue.

The most conspicuous change in the affected muscles was a reduction in size and weight. The extent of this atrophy for the different muscles is given in Table I. In the group most severely affected by the amputation (Group 1), the weight loss varied from 53 to $62 \%$ while the atrophy in the Group 2 muscles varied from 50 to $69 \%$ (palmaris longus $39 \%$ ). The marked atrophy in the latter group
TABLE I

WEIGHT LOSS

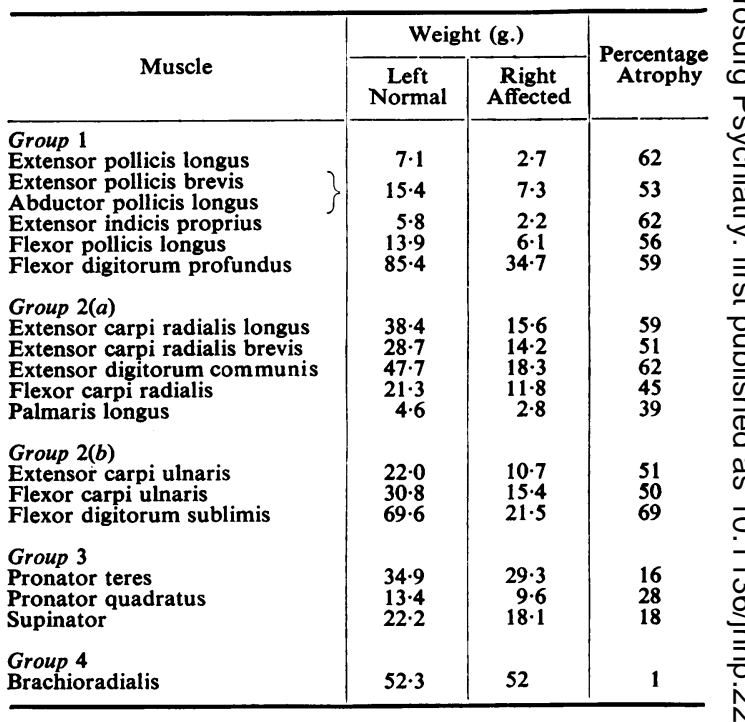

suggests that these muscles were not significantlyo affected by movement at the elbow joint.

The pronator teres and supinator which joineof the radius and ulna but were also attached to the lower end of the humerus showed an atrophy of $1 \mathbb{E} \geq$ and $18 \%$ respectively. On the other hand, the pronator quadratus, which was attached solely to of the radius and ulna, had atrophied by $28 \%$. It io $\overrightarrow{0}$

TABLE II

PERCENTAGE WeIgHT LOSS IN ANIMALS

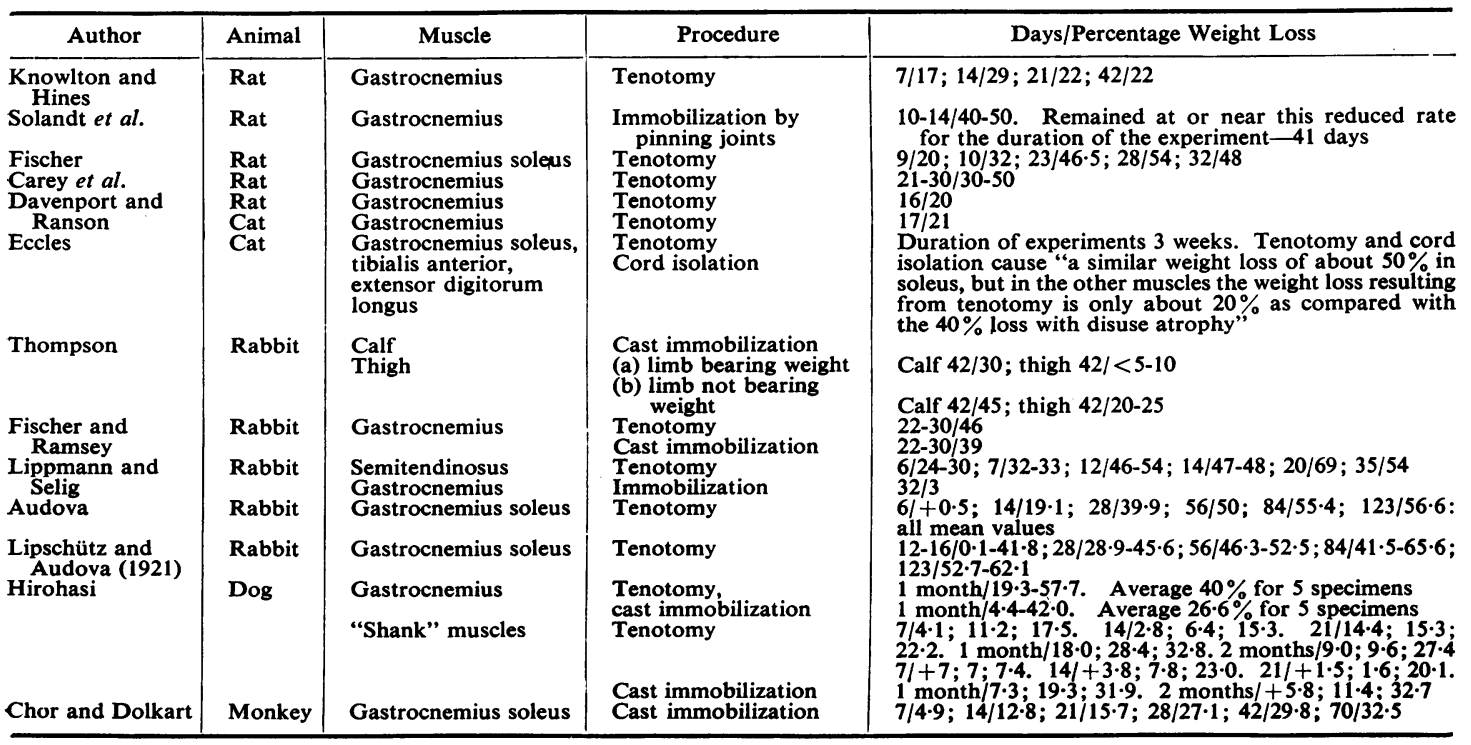


possible that free elbow movement may have been responsible for some of the difference in weight loss between the two groups though this difference is hardly significant.

In contradistinction to the foregoing muscles the weight of the brachioradialis, which functions as a flexor of the elbow joint and was unaffected by the operation, differed by $1 \%$ on the two sides which is well within the range of normality.

A comparison of the atrophy recorded for Groups 1 and 2 on the one hand and Group 3 on the other does, however, reveal a correlation between the degree of the atrophy and the relationship of the muscles to functioning joints. The atrophy was greatest in those muscles which were not, or were but little, affected by joint movements and least marked in those of which the physiology was constantly and significantly modified by such movements (Group 3). In other words, the degree of atrophy was related to the amount of disuse to which the muscle was subjected.

The findings for the tenotomized human muscles are in general agreement with those reported for experimental animals (see Table II) by Audova (1922), Lippmann and Selig (1928), Chor and Dolkart (1936), Hirohasi (1938), Fischer (1941), and Eccles (soleus, 1944), but the weight loss was somewhat greater in the human material than that recorded by Thompson (1934), Chor and Dolkart (1936), Hirohasi (1938), Solandt, Partridge, and Hunter (1943), Fischer and Ramsey (1946), but Carey, Haushalter, Massopust, Garofalo, Lynch, Tabat, and Socoloff (1947), Davenport and Ranson (1930), Knowlton and Hines (1940), and Eccles (tibialis anterior and extensor digitorum longus, 1944), on the other hand, reported a much less severe atrophy in their material. It is to be remembered, however, that the duration of the tenotomy in the human material was very much greater than that employed in any of the experimental investigations.

\section{MICROSCOPIC FEATURES OF THE TENOTOMIZED MUSCLES}

The general overall pattern of the muscle as seen in transverse section was retained.

\section{Reaction of the Extrafusal Fibre to Tenotomy}

Calibre.-The most characteristic change in the morphology of the fibre involved a loss of sarcoplasm and a reduction in its calibre (Figs. 1 to 4 ). Though this atrophy was generalized throughout the muscles examined, some fibres were affected more than others in the same muscle while individual variations in the degree of atrophy among fibres in the same bundle were not uncommon (Figs. 1, 2). Others to comment on these irregularities were Thompson (1934), Tower (1937), and Carey et al. (1947). In some regions the atrophy was extreme, all the fibres being threadlike and in obvious contrast to the surrounding fibres.

Fibre atrophy was observed by Krauss (1888), Chor and Dolkart (1936), and Tower (1937), but Davenport and Ranson (1930) stated that "the atrophy which was indicated by loss of weight was not apparent microscopically" nor could Smith (1928) find any evidence of fibre atrophy.

Subsarcolemmal Nuclei.-The nuclei appeared to be unaltered by tenotomy. Round, oval, and extremely elongated forms were seen, the nucleoli were not increased, and there was no evidence of mitotic activity. Centrally placed nuclei were present but these were no more numerous than in the controls. In this respect the flexor digitorum sublimis was exceptional in that it presented large numbers of central nuclei associated with a high proportion of thin muscle fibres. Deeply situated nuclei were reported by Davenport and Ranson (1930) in both normal and affected muscles.

Tower (1937) described a progressive atrophy and disappearance of the subsarcolemmal nuclei, Froboese (1922) a nuclear increase, and Davenport and Ranson (1930) "A slight but not marked increase", with the nuclei in some fibres appearing a little swollen and staining a little less intensely than normal. On the other hand Krauss (1888) could not detect any nuclear proliferation, while Chor and Dolkart (1936) reported the fibre nuclei as being "not obviously increased in number nor altered in size" and without evidence of mitosis.

Striations.-The striations (Fig. 3) were not uniformly stained in either the normal or the affected muscles which made it difficult to determine whether their absence or fading in the latter was to be attributed to the tenotomy or to vagaries in the staining. It is an impression only that myofibrils lacking in distinct cross striations were more common in the affected muscles. Both transverse and longitudinal striations were, however, well preserved in most of the fibres of all the affected muscles and were often more intensely stained than in the normal fibres. In the poorly stained fibres the longitudinal fibrillation was more distinct than the cross striation. Hensen's discs were clearly visible in the well-stained fibres.

The cross striations were preserved in Chor and Dolkart's (1936) material but they were unable to observe longitudinal striations. On the contrary, the longitudinal striation was more pronounced and the cross striation blurred in Davenport and 


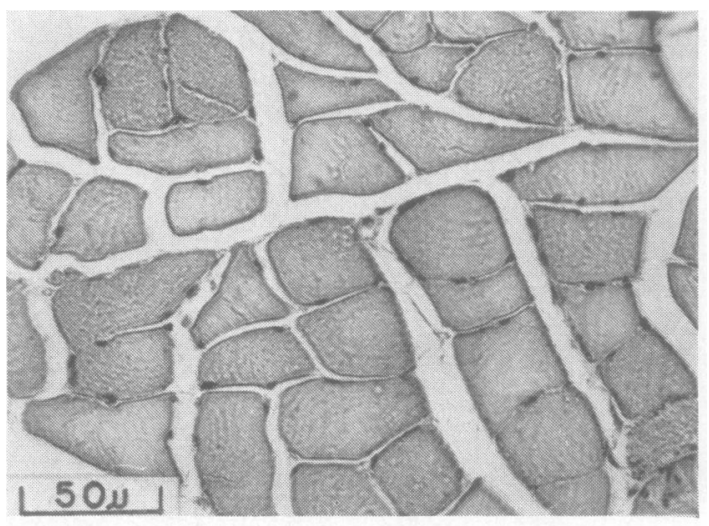

(a)

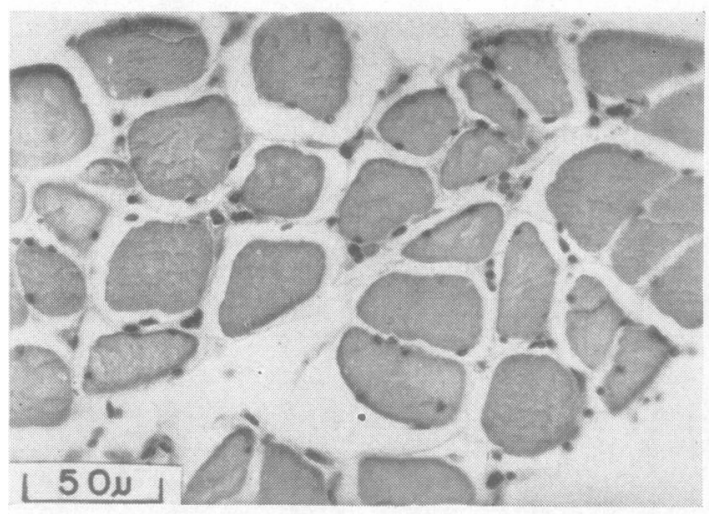

(b)

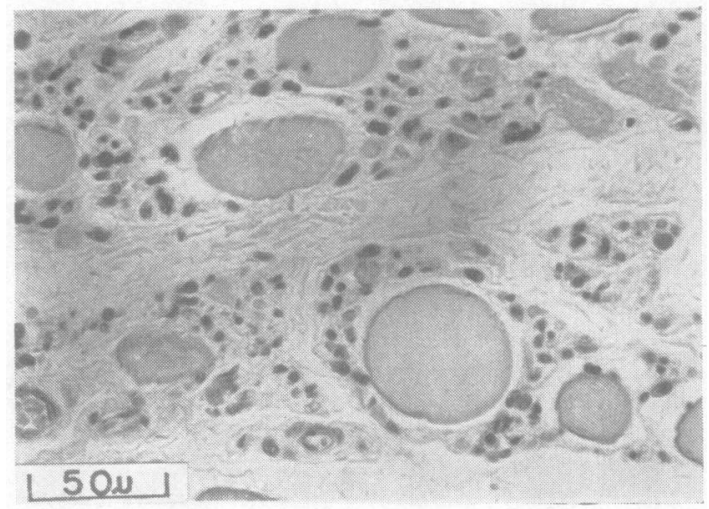

(c)

FIG. 1.-Transverse sections from the normal (a), and tenotomized (b, c; percentage atrophy 69 ) flexor digitorum sublimis muscle.

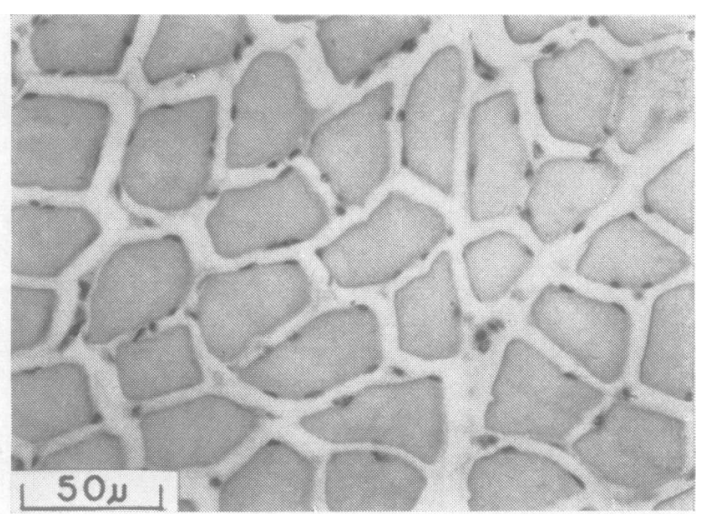

(a)

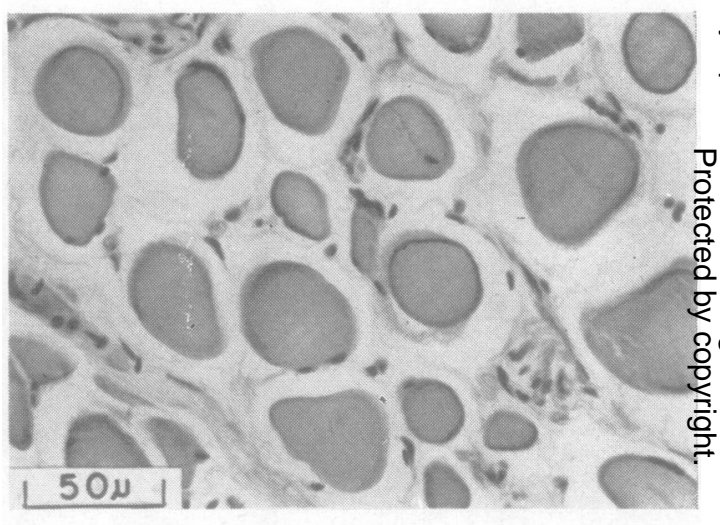

(b)

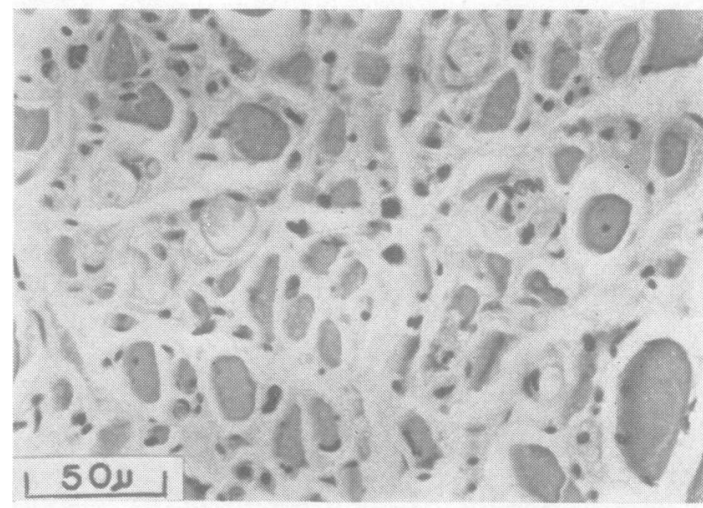

(c)

Fig. 2.-Transverse sections from the normal (a), and tenotomized (b, c; percentage atrophy 62) extensor indicis proprius muscle.

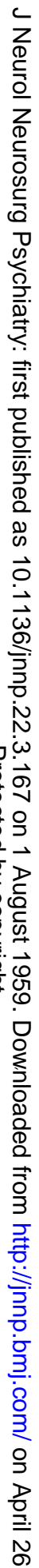

กิ

స్ట श्र 


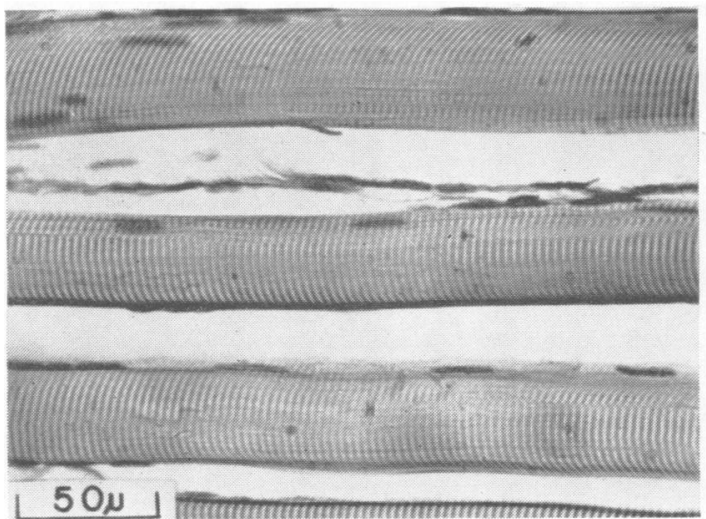

(a)

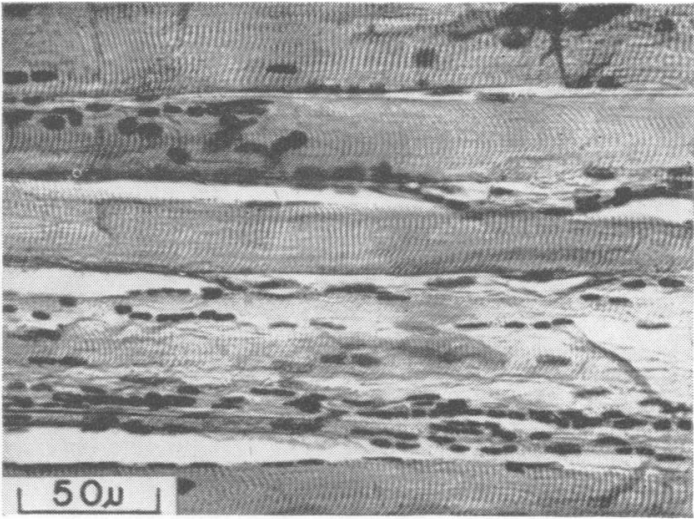

(b)

FIG. 3.- Longitudinal sections of muscle fibres from the normal (a) and tenotomized (b; percentage atrophy 62) extensor pollicis longus muscle.

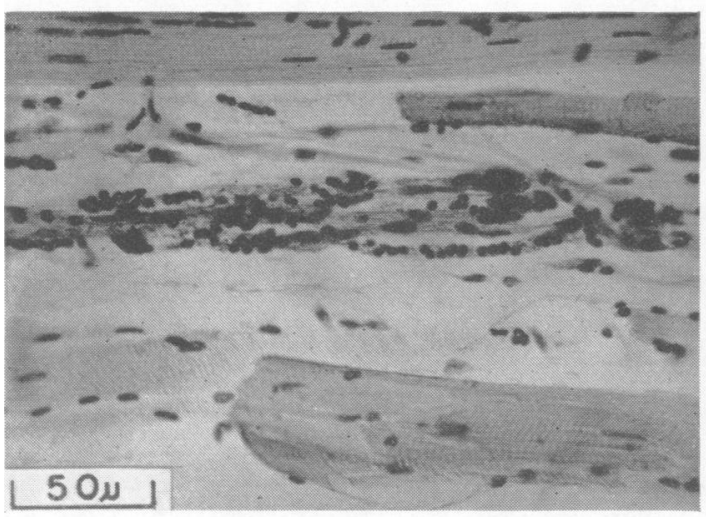

(a)

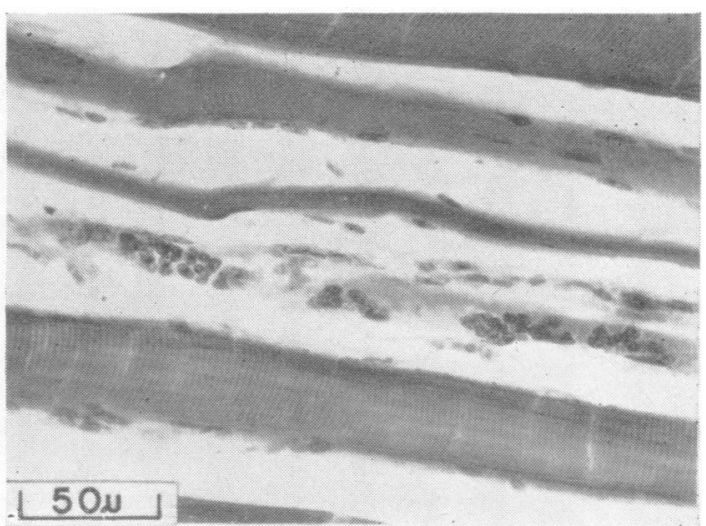

(b)

Fig. 4.-Longitudinal sections showing nuclear aggregations in and about degenerated muscle fibres from the tenotomized extensor indicis proprius (a) and flexor digitorum sublimis (b) muscles.

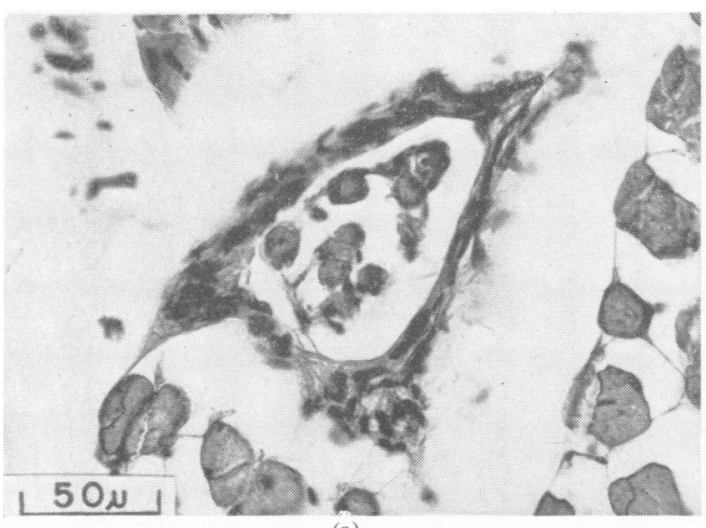

(a)

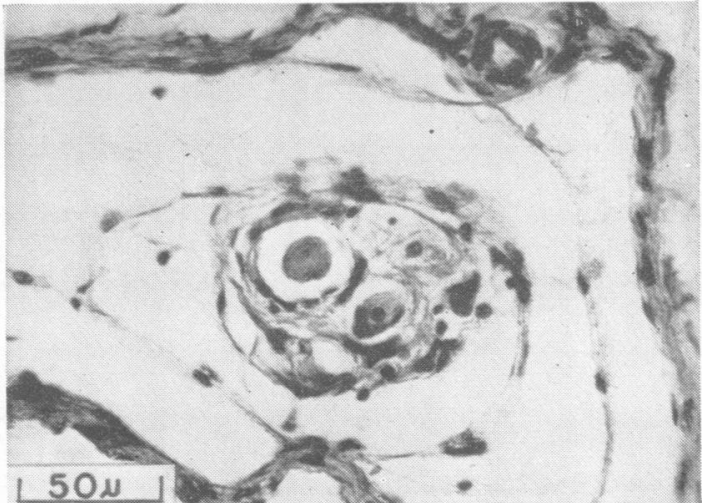

(b)

FIG. 5.-Transverse sections of spindles from the normal (a) and tenotomized (b) extensor carpi ulnaris muscle. 
Ranson's (1930) material. Tower (1937) describes paling of the cross striation which, however, endured "to the end".

End Plates.-We are unable to state whether or not there was any reduction in the number of plates but the examination of large numbers of sections indicated that atrophied fibres carried end plates which showed no significant change in their morphology. These findings agree with those of Chor and Dolkart (1936). According to Tower (1937) "sole plate nuclei maintain their size and numbers until abruptly they disappear", though progressive failure to stain and the disorganization of neuromuscular relations with advanced atrophy were also described. We were unable to detect any signs of disintegrating plates though such evidence is unlikely to survive 20 years after amputation.

Muscle Fibre Degeneration.-There was evidence of some degeneration in addition to atrophy of fibres (Figs. 1, 2, and 4). This degeneration was observed among the fibres showing the most extreme atrophy. Here thread-like fibres had fragmented into segments by a process of vacuolation and this change was accompanied by a round cell reaction. Aggregations of large, round to oval, palely staining nuclei occurred at intervals along the degenerating fibres and were interpreted as persisting muscle and end plate nuclei. Foci of degeneration were observed in the flexor digitorum sublimis, extensor pollicis longus, extensor carpi ulnaris, and extensor indicis proprius muscles. These areas of degeneration were not, however, a characteristic feature of the sections.

Smith (1928), Davenport and Ranson (1930), and Chor and Dolkart (1936) could not detect any degeneration of muscle fibres. On the other hand, Froboese (1922) reports a fatty degeneration and replacement by connective tissue while Thompson (1934) saw an occasional degenerating fibre. Tower (1937) has reported the most profound changes during which "by progressive loss of muscle substance and nuclei and paling of cross striation, muscle fibres are metamorphosed into tendon-like fibres and muscle tissue into fibrous tissue".

\section{The Neuromuscular Spindle}

Spindles could be readily identified in all the affected muscles and did not differ qualitatively from those of the normal muscles (Fig. 5). The capsule was composed of a relatively thin sheath of connective tissue which was clearly distinct from the surrounding intramuscular connective tissue. The periaxial space was patent and well defined. Each spindle contained several intrafusal fibres which were normal in appearance though some atrophy could not be excluded. There was no evidence of degeneration in any of the spindles examined.

According to Tower (1937) "the spindles share in the general fibrosis but appear otherwise unaffected" while the thin intrafusal fibres do not atrophy; in 0 densely fibrotic and degenerating areas, however, the spindles were much altered.

\section{Connective Tissue}

It was obvious from an examination of the sections that there was a differential effect on the $\overrightarrow{0}$ two chief components of the muscles, namely, $\frac{\bar{O}}{\bar{D}}$ the muscle fibres and supporting tissue (Figs. 1 and $\frac{\bar{\sigma}}{\frac{1}{2}}$ 2). After tenotomy the relative areas of the two, as $\Phi$ seen in a histological section, are changed and with

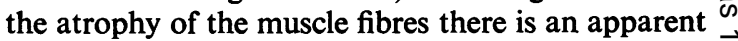
increase in the connective tissue framework of the $\vec{\circ}$ muscle. This effect was generalized but occurred $\overrightarrow{\vec{\omega}}$ maximally in association with the areas of extreme $\underset{\sigma}{\omega}$ atrophy and muscle fibre degeneration where the $\overline{\overrightarrow{3}}$ connective tissue elements overshadowed the sur- $\frac{7}{0}$ viving muscle fibres. Thickening of the perivascular $N$ connective tissue was also well marked. The changes $\omega$ involved an increase in the thickness of the endomy $\vec{\sigma}$ sium and perimysial septa, with duplication ang reduplication of the collagen fibres between the muscle fibres and a marked increase in the nucle학of fibroblasts and small round cells. These changes were specially noticeable in the extensor indic proprius, flexor digitorum sublimis, extensor pollic longus, and extensor carpi ulnaris while they wete relatively slight in the extensor carpi radialis longus. of

In order to obtain quantitative data on the relative distribution of muscle tissue and connective tissue in the muscles the sections were analysed by a method introduced by Chalkley (1943) for "measuring directly the area ratios of components of tissues or organs under any conditions, where the various components are clearly distinguishable visually". 웅 This analysis revealed a reduction in the amount of 3 muscle tissue and an increase in the amount of connective tissue in the affected muscles relative to one another. The next point to be determined is whether this increase is relative or real. Having? obtained the area ratios for muscle and connective $\frac{9}{3}$ tissue the total weight of each in the muscle was then obtained by multiplying the weight of the whole muscle by the percentage of muscle and of connective tissue. In arriving at these values certain 음 assumptions were made, namely:-

(a) That the cross section of a muscle presents a reasonably representative picture of conditions pre- $\bar{N}$ vailing in the muscle as a whole. The ideal method would be to determine the relative areas of muscle $\tilde{O}$ and supporting tissue in each of a complete set of $\underset{\omega}{\tilde{N}}$ 
serial sections. Obviously this was not a practicable proposition in these muscles.

(b) That the relative water content of the two was the same.

With these assumptions in mind, the calculations revealed that the increase in connective tissue was relative and not absolute. There was in fact an overall reduction in the amount of connective tissue as well as of the muscle tissue, the reduction, however, being much greater in the case of the latter. The following values were obtained:

Percentage loss of muscle

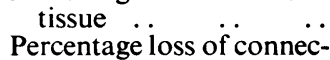

tive tissue

$\left.\begin{array}{l}60 \text { to } 83 \\ 32 \text { to } 43\end{array}\right\} \begin{gathered}\text { depending on } \\ \text { the } \\ \text { muscle }\end{gathered}$

The extensor carpi radialis longus was exceptional in that it showed a $59 \%$ loss in muscle tissue and a $60 \%$ loss in connective tissue.

An "increase" in connective tissue was an outstanding feature in Krauss' (1888) and Tower's (1937) material and was also reported by Froboese (1922). Thompson (1934) saw a few areas showing marked fibrosis but Ricker (1901) and Chor and Dolkart (1936) were unable to detect any increase. According to Davenport and Ranson (1930) there was "no increase of connective tissue that can be demonstrated histologically" though "it seems possible that a change may have taken place in the character of the connective tissue without an actual increase in quantity".

\section{Vascular Changes}

There were no abnormalities in the vessels or vascular pattern in our material other than the perivascular connective tissue thickening referred to earlier. Chor and Dolkart (1936) reported normal vessels. Tower (1937) could not detect any thickening of the endothelium such as she observed after denervation, though she also observed a deposition of fibrous tissue on the outside of some vessels.

\section{Intramuscular Nerves}

Tower (1937) reported a fibrosis which enveloped but did not invade the nerve fibres which were "almost entirely intact" and Chor and Dolkart (1936) described nerve fibres which were normal in appearance. There were no abnormalities in the sections examined by us.

\section{General}

It is impossible to reconcile the findings reported in this paper with those described by Tower who concluded that

"regardless of the condition determining disuse of muscle, whether denervation or inactivation without denervation, whether in the course of phylogenesis or in the span of individual life, the result of disuse appears to be invariant - the muscle slowly atrophies and fibrous tissue takes its place."
It is true that there were patchy areas of degeneration in some of the material examined by us but these were not a characteristic feature of the sections. On the contrary, the general outlines of the tenotomized muscles were preserved and the picture was one in which the great majority of the fibres survived with alterations in structure which did not, however, destroy those morphological features upon which the identification of muscle tissue depends. The most conspicuous change was a reduction in size and weight of the affected muscles which was reflected in a substantial atrophy of the muscle fibres, the degree of atrophy, however, varying from fibre to fibre in the same bundle and in different parts of the same muscle. The connective tissue was also reduced in amount but not to the same extent as the muscle tissue so that in the preparations the former was relatively increased in comparison with the latter. Our findings are therefore more in accord with those of Chor and Dolkart (1936) who concluded that "Disuse atrophy consists primarily of a uniform reduction of the bulk of each muscle cell.... This type of atrophy is associated with very simple structural changes".

A final point of interest concerns the duration of the tenotomy, namely 20 years, from which it may be inferred that the findings in this material represent the end-point of theatrophic change in human muscle.

\section{SUMMARY}

Weight loss and histological studies have been made on the tenotomized muscles of amputation stumps in man and on other muscles of which the attachments were undisturbed but the activities curtailed by the amputation.

The general outlines of the tenotomized muscles were preserved and the great majority of the fibres survived with alterations in structure which did not, however, destroy those morphological features upon which the identification of muscle tissue depends.

The affected muscles were reduced in size and weight. The extent of this atrophy was related to the amount of disuse to which the muscle was subjected. The atrophy in the tenotomized muscles varied from 39 to $69 \%$ and in the muscles of which the functions had been curtailed from 16 to $28 \%$.

Histologically the essential change was of a simple atrophy of the muscle fibres. The weight loss was reflected in a substantial atrophy of the muscle fibres which was generalized but not uniform throughout the muscles. Some fibres suffered more than others in the same muscle and in the same fasciculus.

Patchy areas of degeneration were observed in sections of some of the muscles but these were not a characteristic feature of the sections. 
The connective tissue was also reduced in amount but not to the same extent as the muscle tissue. The differential effect was such that the former was relatively increased with reference to the latter.

The neuromuscular spindles and intramuscular blood vessels and nerves appeared normal.

The duration of the tenotomy in the material investigated was one and 20 years. From this it is inferred that the findings represent the end-point of the atrophic change in human muscle after tenotomy.

\section{REFERENCES}

Audova, A. (1922). Schweiz. Arch. Neurol. Psychiat., 10, 211.

Carey, E. J., Haushalter, E., Massopust, L. C., Garofalo, F., Lynch, J., Tabat, D., and Socoloff, E. (1947). Proc. Soc. exp. Biol. (iN.Y.), 64, 193 .
Chalkley, H. W. (1943). J. nat. Cancer Inst., 4, 47.

Chor, H., and Dolkart, R. E. (1936). Amer. J. Physiol., 117, 626. Davenport, H. K., and Ranson, S. W. (1930). Arch. Surg. (Chicago), 21, 995 .

Eccles, J. C. (1944). J. Physiol. (Lond.), 103, 253.

Fischer, E. (1941). Proc. Soc. exp. Biol. (N.Y.), 47, 277.

, and Ramsey, V. W. (1946). Amer. J. Physiol, 145, 571.

Froboese, C. (1922). Mitt. Grenzgeb. Med. Chir., 35, 683.

Hirohasi, S. (1938). Jap. J. med. Sci. III, Biqphysics, 5, 367.

Knowlton, G. C., and Hines, H. M. (1940). Amer. J. Physiol., 128, 521.

Krauss, E (1888) Virchows Arch. path. Anat., 113, 315.

Langley, J. N. (1916).J. Physiol. (Lond.), 50, 335.

Langley, (1917). Ibid., 51, 377 .

二, and Hashimoto, M. (1918). Ibid., 52, 15.

Lippmann, R. K., and Selig, S. (1928). Surg. Gynec. Obstet., 47, 512 .

Lipschütz, A., and Audova, A. (1921). J. Physiol. (Lond.), 55, 300.

Ricker, G. (1901). Virchows Arch. path. Anat., 165, 263.

Smith, N. R. (1928). J. Anat. (Lond.), 62, 238.

Solandt, D. Y., Partridge, R. C., and Hunter, J. (1943). J. Neurophysiol., 6, 17

Thompson, T. C. (1934). J. Bone J. Surg., 16, 564.

Tower, S. S. (1937). J. comp. Neurol., 67, 241.

\section{THE MAY (1959) ISSUE}

The May (1959) issue contains the following papers:-

The Two Components of the Grasp Reflex after Ablation of Frontal Cortex in Monkeys. Geoffrey Rushworth and D. Denny-Brown.

Congenital Hydrocephalus with Defective Development of the Cerebellar Vermis (Dandy-Walker Syndrome A. Brodal and E. Hauglie-Hanssen.

A Method for the Localization and Production of Discrete Destructive Lesions in Brain. I. R. McCaul.

The Effects of Induced Hyperthermia on Patients with Multiple Sclerosis. Dewey A. Nelson and Fletcher McDowell.

The Cholesterol and Cholesterol Ester Content of Cerebrospinal Fluid in Patients with Multiple Sclerosis and Other Neurological Diseases. Joseph B. Green, Nicholas Papadopoulos, William Cevallos, Francis M. Forster, and Walter C. Hess.

Acute Demyelinating Disease Complicating Herpes Zoster. Douglas McAlpine, Y. Kuroiwa, Y. Toyokura, and S. Araki.

Prosopagnosia. B. Bornstein and D. P. Kidron.

The Value of Leucotomy in Relation to Diagnosis. A. A. Robin.

The Effects of Meprobamite and Pentobarbitone Sodium on Sleep and Motility during Sleep: A Controlled Trial with Psychiatric Patients. J. M. Hinton and E. Marley.

Paraplegia Caused by Extraspinal Metastasis from a Uterine Fibroid. Lambert Rogers and Lewis Thomas.

Neurological Aspects of Leptospirosis. R. W. Ross Russell.

Book Reviews.

A number of copies are still available and may be obtained from the Publishing Manager, British $\underset{\omega}{\mathcal{N}}$ Medical Association, Tavistock Square, W.C.1, price 17s. $6 d$. 